\title{
Editorial \\ Integration and Control of Distributed Renewable Energy Resources
}

\author{
Hamidreza Nazaripouya ${ }^{1,2}$ (D) \\ 1 School of Electrical and Computer Engineering, Oklahoma State University, \\ Stillwater, OK 74078, USA; hanazar@okstate.edu \\ 2 Department of Electrical and Computer Engineering, University of California, Riverside (UCR), \\ Riverside, CA 92507, USA
}

Citation: Nazaripouya, $\mathrm{H}$. Integration and Control of

Distributed Renewable Energy

Resources. Clean Technol. 2022, 4,

149-152. https://doi.org/10.3390/

cleantechnol4010010

Received: 7 February 2022

Accepted: 24 February 2022

Published: 1 March 2022

Publisher's Note: MDPI stays neutral with regard to jurisdictional claims in published maps and institutional affiliations.

Copyright: (C) 2022 by the author. Licensee MDPI, Basel, Switzerland. This article is an open access article distributed under the terms and conditions of the Creative Commons Attribution (CC BY) license (https:// creativecommons.org/licenses/by/ $4.0 /)$.

\section{Introduction}

The increase in the population growth rate and the motivation to overcome issues such as environmental concerns and air pollution have made distributed renewable energy resources (DRER) the most popular option for providing the required energy. In addition, DRER, by making technologies such as microgrid feasible, facilitate the expansion of the power network to disadvantaged communities as well as remote and rural areas, which are not connected to the main grid. At the same time, they can improve the operation, resilience, and efficiency of the power grid by providing extra flexibility, local energy supply, and lower energy loss [1,2].

However, there are still several technical and non-technical challenges regarding interconnection of renewables into the grid [3]. The current power grid is aging and faces a future for which it was not designed. For instance, with the widespread proliferation of rooftop solar, distribution utilities have consumers who become "prosumers" as they consume and produce electricity at the same time [4]. However, the traditional electric power grid has been designed for power flow in one direction. As the penetration of distributed renewable energy resources such as solar or wind increases, it is anticipated that in some feeders, the flow of power changes to the "reverse direction" [5]. In addition, the power fluctuations of DRER adversely affect the operation of power systems [6]. From the grid perspective, technical concerns associated with the high penetration of renewables with intermittent nature include energy management $[7,8]$, forecasting $[9,10]$, power quality (e.g., variations of voltage and harmonic issues) [5], grid stability [11], reliability, and protection issues.

Moreover, still many aspects of DRER deployment are nascent, for which there are no standards or accepted best practices [12]. For example, the deployment of DRER increases the number of grid-edge devices that are typically equipped with communication and control interfaces for remote access and control. These emerging grid-edge devices introduce new vulnerabilities to the gid when it comes to cyber-physical attacks. From the DRER perspective, the technical challenges range over a wide spectrum of topics including technoeconomic feasibility analysis, technology selection, software/hardware design, modeling, planning, sizing and placement, grid support capability, cyber-physical security, and interoperability at the component level and system level.

On the other hand, the non-technical challenges can be classified in three categoriesregulatory issues, social issues, economic issues. Regarding regulatory issues, impotent policies, lack of standards and regulations, complex administrative procedures, and sometimes the gap between policy targets and reality, are some examples. Social issues include, but not limited to, lack of public awareness and information, lack of technically skilled labor, and adverse impacts on other/alternative sources of income. Competition with fossil fuel, lack of effective incentives and subsidies, high capital cost, and challenges in securing financing are some existing economic issues [13]. 
To overcome the existing technical and non-technical challenges, considerations should be taken into account for integration and control of DRER. Understanding these considerations across a wide range of topics associated with DRER deployment as well as becoming familiar with emerging practices and solutions pave the path to achieving a high level of renewable penetration in power systems.

\section{A Short Review of the Contributions in This Issue}

This Special Issue is focused on "Integration and Control of Distributed Renewable Energy Resources" and aims to identify some of the considerations and new practices for interconnection and operation of DRER in different applications. Topics addressed in this Special Issue include technology selection of photovoltaics (PV) for optimal operation of solar-powered electric vehicle charging facilities, design of small-scale wind turbines for residential applications, hosting capacity analysis of solar PV systems in distribution grids, optimal allocation of DRER in a distribution network, resilient operation of distributed energy resources in a distribution grid, hardware control of a hybrid wind-PV-battery power-generation system, and finally control of single-phase inverter-interfaced DRER to achieve a desired interphase power flow / routing.

In this issue, a total of seven papers were published, covering different aspects of integration and control of DRER including technology selection, design, techno-economic analysis, planning, management, and operation.

Four papers are focused on control and optimization of DRER operation. The first one developed a composite control strategy for off-grid operation of a hybrid wind-solarbattery-diesel power-generation system [14]. Some features of the proposed control include speed sensorless operation of a variable-speed wind turbine, stable operation of the system during disturbances, enhanced power quality at the point of connection under nonlinear loads, and extraction of maximum power from PV without using any maximum power point tracking (MPPT) algorithm [14]. The second paper proposed an interphase power flow (IPPF) control for line-to-line single-phase power electronic-interfaced DRER [15]. The IPPF controller allows single-phase elements to route active power between phases, improving system operation and flexibility. The IPPF control was also applied to a utility distribution circuit, which led to reductions in system voltage unbalance and losses through balancing the active power at the feeder head. The third one [16] considered four different PV panel technologies and optimized the operation of Solar PV systems in an electric vehicle charging center. The profit of the charging facility was maximized considering solar radiation uncertainty and different behaviors of EV owners as well as several weather conditions. Finally, a model-based predictive control (MPC) strategy was proposed for power flow management in a power distribution system with PV power generation [17]. The optimization problem is subject to voltage constraints and assets' operational restrictions. A forecasting module based on a Gaussian process regression model was constructed to predict the global horizontal irradiance (GHI), grid load, and water demand. It was shown that the proposed MPC strategy is resilient to errors of the forecasting module. A min-max problem was added on top of the main optimization problem to minimize voltage overflow, which also enhances the resilience of the strategy.

The investigation into optimized allocation of distributed energy resources (DERs) in distribution systems with the goal of minimizing the system loss was pursued in [18]. A hybrid optimization approach, composed of the tunicate swarm algorithm (TSA) and the sine-cosine algorithm (SCA), was introduced to identify the best size and location of DERs in the system. The optimization process is performed for DERs in three different modes: active power production ( $\mathrm{P}$-mode), reactive power production $(\mathrm{Q}$ mode), and active and reactive power production (PQ-mode). Authors in [19] conducted an investment analysis for integration of a small-scale wind turbine into residential homes. Their studies show that relying only on software tools may mislead investors during the decision-making process, as in most of these tools, installation costs, maintenance costs, net metering options, and taxation schemes are not included. The focus in [20] is on assessing the threshold of PV 
penetration, known as hosting capacity (HC) of PV integration, in low-voltage distribution systems. To this end, the HC values of three types of networks in rural, suburban, and urban regions for different $\mathrm{HC}$ reference definitions were compared. The comparison was made under balanced and unbalanced PV deployment scenarios and different load conditions. Monte Carlo (MC) simulations and stochastic analysis were utilized to include the effect of PV power intermittency and varying loading conditions in the assessment.

\section{Conclusions}

In the 21st-century technological race for power-grid modernization, DRER provide an opportunity to help shape the future of our nation's energy supply while improving the reliability, resilience, affordability, flexibility, and security of the electric power grid, and providing a chance to solve the corresponding economic, environmental, and social problems. The diverse contributions in this Special Issue make it evident that the deployment of distributed renewable energy resources is a vast topic and has many aspects to be studied in detail. As the demand and interest for producing clean energies are growing rapidly, there is a need to understand considerations for interconnection and control of distributed renewable resources. This Special Issue aimed to shed some light on some key issues as well as potential solutions in DRER integration and control.

Funding: This research received no external funding.

Institutional Review Board Statement: Not applicable.

Informed Consent Statement: Not applicable.

Data Availability Statement: Not applicable.

Acknowledgments: The Guest Editor sincerely appreciates all the authors in this Special Issue for their efforts and valuable contributions.

Conflicts of Interest: The authors declare no conflict of interest. Additionally, the funders had no role in the design of the study; in the collection, analyses, or interpretation of data; in the writing of the manuscript, or in the decision to publish the results.

\section{References}

1. Nazaripouya, H.; Pota, H.R.; Chu, C.-C.; Gadh, R. Real-Time Model-Free Coordination of Active and Reactive Powers of Distributed Energy Resources to Improve Voltage Regulation in Distribution Systems. IEEE Trans. Sustain. Energy 2020, 11, 1483-1494. [CrossRef]

2. Nazaripouya, H. Grid Resilience and Distributed Energy Storage Systems. IEEE Smart Grid Newsl. Smart Grid Appl. Enhanc. $2019,17$.

3. Nazaripouya, H. Integration and Control of Battery Energy Storage and Inverter to Provide Grid Services. Ph.D. Thesis, University of California, Los Angeles, CA, USA, 2017.

4. Azar, A.G.; Nazaripouya, H.; Khaki, B.; Chu, C.C.; Gadh, R.; Jacobsen, R.H. A Non-Cooperative Framework for Coordinating a Neighborhood of Distributed Prosumers. IEEE Trans. Ind. Inform. 2018, 15, 2523-2534. [CrossRef]

5. Nazaripouya, H.; Wang, Y.; Chu, P.; Pota, H.R.; Gadh, R. Optimal Sizing and Placement of Battery Energy Storage in Distribution System Based on Solar Size for Voltage Regulation. In Proceedings of the 2015 IEEE PES General Meeting, Denver, CO, USA, 26-30 July 2015.

6. Nazaripouya, H.; Chu, C.-C.; Pota, H.R.; Gadh, R. Battery Energy Storage System Control for Intermittency Smoothing Using an Optimized Two-Stage Filter. IEEE Trans. Sustain. Energy 2018, 9, 664-675. [CrossRef]

7. Wang, Y.; Nazaripouya, H. Demand-Side Management in Micro-Grids and Distribution Systems: Handling System Uncertainties and Scalabilities. In Classical and Recent Aspects of Power System Optimization; Zobaa, A.F., Aleem, S.H., Abdelaziz, A.Y., Eds.; Elsevier Inc.: London, UK, 2018.

8. Wang, Y.; Wang, B.; Zhang, T.; Nazaripouya, H.; Chu, C.C.; Gadh, R. Optimal energy management for Microgrid with stationary and mobile storages. In Proceedings of the 2016 IEEE/PES Transmission and Distribution Conference and Exposition (T\&D), Dallas, TX, USA, 3-5 May 2016; pp. 1-5.

9. Nazaripouya, H.; Wang, B.; Wang, Y.; Chu, P.; Pota, H.R.; Gadh, R. Univariate time series prediction of solar power using a hybrid wavelet-ARMA-NARX prediction method. In Proceedings of the 2016 IEEE/PES Transmission and Distribution Conference and Exposition (T\&D), Dallas, TX, USA, 3-5 May 2016.

10. Majidpour, M.; Nazaripouya, H.; Chu, C.; Pota, H.R.; Gadh, R. Fast Univariate Time Series Prediction of Solar Power for Real-Time Control of Energy Storage System. Forecasting 2018, 1, 107-120. [CrossRef] 
11. Saberi, H.; Nazaripouya, H.; Mehraeen, S. Implementation of a Stable Solar-Powered Microgrid Testbed for Remote Applications. Sustainability 2021, 13, 2707. [CrossRef]

12. Horowitz, K.; Peterson, Z.; Coddington, M.; Ding, F.; Sigrin, B.; Saleem, D.; Schroeder, C. An Overview of Distributed Energy Resource (DER) Interconnection: Current Practices and Emerging Solutions; National Renewable Energy Laboratory (NREL): Golden, CO, USA, 2019.

13. Seetharaman; Moorthy, K.; Patwa, N.; Saravanan; Gupta, Y. Breaking Barriers in Deployment of Renewable Energy. Heliyon 2019, 5, e01166. [CrossRef] [PubMed]

14. Rezkallah, M.; Ibrahim, H.; Dubuisson, F.; Chandra, A.; Singh, S.; Singh, B.; Issa, M. Hardware Implementation of Composite Control Strategy for Wind-PV-Battery Hybrid Off-Grid Power Generation System. Clean Technol. 2021, 3, 821-843. [CrossRef]

15. Siratarnsophon, P.; Cunha, V.C.; Barry, N.G.; Santoso, S. Interphase Power Flow Control via Single-Phase Elements in Distribution Systems. Clean Technol. 2021, 3, 37-58. [CrossRef]

16. Farahmand, M.Z.; Javadi, S.; Sadati, S.M.; Laaksonen, H.; Shafie-khah, M. Optimal Operation of Solar Powered Electric Vehicle Parking Lots Considering Different Photovoltaic Technologies. Clean Technol. 2021, 3, 503-518. [CrossRef]

17. Dkhili, N.; Eynard, J.; Thil, S.; Grieu, S. Resilient Predictive Control Coupled with aWorst-Case Scenario Approach for a Distributed-Generation-Rich Power Distribution Grid. Clean Technol. 2021, 3, 629-655. [CrossRef]

18. Awad, A.; Abdel-Mawgoud, H.; Kamel, S.; Ibrahim, A.A.; Jurado, F. Developing a Hybrid Optimization Algorithm for Optimal Allocation of Renewable DGs in Distribution Network. Clean Technol. 2021, 3, 409-423. [CrossRef]

19. Ribbing, S.; Xydis, G. Renewable Energy at Home: A Look into Purchasing a Wind Turbine for Home Use-The Cost of Blindly Relying on One Tool in Decision Making. Clean Technol. 2021, 3, 299-310. [CrossRef]

20. Fatima, S.; Püvi, V.; Lehtonen, M. Comparison of Different References When Assessing PV HC in Distribution Networks. Clean Technol. 2021, 3, 123-137. [CrossRef] 